\title{
Failure of fertility therapy and subsequent adverse cardiovascular events
}

\author{
Jacob A. Udell MD MPH, Hong Lu PhD, Donald A. Redelmeier MD MSHSR
}

Cite as: CMAJ 2017 March 13;189:E391-7. doi: 10.1503/cmaj.160744

CMAJ Podcasts: author interview at https://soundcloud.com/cmajpodcasts/160744-res

\begin{abstract}
BACKGROUND: Infertility may indicate an underlying predisposition toward premature cardiovascular disease, yet little is known about potential long-term cardiovascular events following fertility therapy. We investigated whether failure of fertility therapy is associated with subsequent adverse cardiovascular events.
\end{abstract}

METHODS: We performed a populationbased cohort analysis of women who received gonadotropin-based fertility therapy between Apr. 1, 1993, and Mar. 31, 2011, distinguishing those who subsequently gave birth and those who did not. Using multivariable Poisson regression models, we estimated the relative rate ratio of adverse cardiovascular events associated with fertility therapy failure, accounting for age, year, baseline risk factors, health care history and number of fertility cycles. The primary outcome was subsequent treatment for nonfatal coronary ischemia, stroke, transient ischemic attack, heart failure or thromboembolism.

RESULTS: Of 28442 women who received fertility therapy, 9349 (32.9\%) subsequently gave birth and 19093 (67.1\%) did not. The median number of fertility treatments was 3 (interquartile range 1-5). We identified 2686 cardiovascular events over a median 8.4 years of follow-up. The annual rate of cardiovascular events was $19 \%$ higher among women who did not give birth after fertility therapy than among those who did (1.08 v. 0.91 per 100 patient-years, $p<0.001$ ), equivalent to a $21 \%$ relative increase in the annual rate (95\% confidence interval 13\%-30\%). We observed no association between event rates and number of treatment cycles.

INTERPRETATION: Fertility therapy failure was associated with an increased risk of long-term adverse cardiovascular events. These women merit surveillance for subsequent cardiovascular events.
$\mathrm{F}$ ertility therapy is increasingly being prescribed for women with infertility. ${ }^{1}$ Repeated cycles are often recommended, with mixed success and possible short-term metabolic risks. ${ }^{2-6}$ However, few data are available on the long-term health effects of fertility therapy, particularly following unsuccessful treatment. ${ }^{7}$ Failure of fertility therapy may be an early indicator of future cardiovascular risk by acting as a unique cardiometabolic stress test. In addition, fertility therapy may lead to adverse cardiovascular events by inducing background thrombosis, activating the renin-angiotensin system or inducing vascular injury from ovarian hyperstimulation. ${ }^{8-16}$ The last mechanism may be further exacerbated in patients who undergo multiple cycles of fertility therapy or experience pregnancy miscarriages. ${ }^{17-21}$ An association between fertility therapy failure and longterm cardiovascular risk could provide insight into nontraditional risk factors potentially contributing to the stagnation in the reduction of cardiovascular mortality observed among young women.22-26

We conducted the Investigation of Notable Failed Endeavours at Reproductive Treatment and Ischemic Long-term Events (INFERTILE) study to investigate whether fertility therapy failure is associated with subsequent adverse cardiovascular events.

\section{Methods}

\section{Study design and participants}

The INFERTILE study was designed as a population-based longitudinal cohort analysis of women aged 50 years or less who received fertility therapy in Ontario, Canada, between Apr. 1, 1993, and Mar. 31, 2011, and were followed until Mar. 31, 2015. Patients were identified through the Ontario Health Insurance Plan (OHIP) database, which encompasses prenatal care as well as hospital and postnatal care. We identified individuals as having received fertility therapy according to whether they had 2 or more claims for supervision of ovulation induction with human menopausal gonadotropins or gonadotropin-releasing hormone (OHIP code G334). ${ }^{2,27}$ If multiple treatments were present, the date of the last treatment was selected for primary analysis. We excluded women who were not residents of Ontario or who lacked a valid health card identifier.

\section{Definition of fertility therapy failure}

We determined whether women did or did not give birth within 1 year after their last fertility treatment using computerized search 
methods to screen for a subsequent newborn delivery (OHIP codes P006, P018 and P020). Overall, the OHIP databases have a high level of completeness (> 99\%) and diagnostic accuracy (> 95\%) in this setting. ${ }^{28,29}$ Fertility therapy failure was defined as cycles of treatment that were not followed by a subsequent newborn delivery within 1 year. Because individuals may have undergone repeated cycles of fertility therapy, we classified each woman by the total number of cycles of treatment by analyzing consecutive 28day blocks to explore potential dose-response relationships.

The available databases lacked information on specific fertility medications because Ontario did not provide single-payer universal coverage for fertility prescriptions. However, human menopausal gonadotropins and gonadotropin-releasing hormone both qualified for OHIP code G334.

\section{Patient characteristics}

We collected baseline data on demographic and clinical characteristics from the Canadian Institute for Health Information hospital and outpatient databases during the 2 years before each woman's final fertility treatment. ${ }^{28}$ The databases also served as the source for identifying follow-up outcomes, admissions and procedures. In addition, we used the hospital database to collect information on the patient's age and sex, date of admission, and additional diagnoses coded with the International Classification of Diseases, 9th revision (ICD-9; 16 diagnoses) or the International Statistical Classification of Diseases and Related Health Problems, 10th revision (ICD-10; 25 diagnoses).

Some diagnoses were primarily identified outside of hospital (e.g., hypertension and diabetes); we used the outpatient database to determine selected diagnoses and aggregate health care utilization accumulated during the 2 years before the final fertility treatment. ${ }^{30,31}$ We estimated the patient's residence location (urban or rural) and neighbourhood income (in quintiles) from the individual's home address. History of live births, miscarriages and stillbirths was ascertained over the duration of available data. We also collected information on history of hypertension, diabetes, hypercholesterolemia, smoking, obesity, gestational hypertension, gestational diabetes, ischemic heart disease, heart failure, atrial fibrillation, asthma, neoplasm and depression, and number of health care visits in the prior 2 years, number of fertility cycles and number of in-vitro fertilization procedures. Information about laboratory test results and prescription medications were not available.

\section{Outcomes}

The primary outcome was a composite of medical care for nonfatal coronary ischemia, acute stroke, transient ischemic attack (TIA), heart failure or thromboembolism. We used ICD-9 codes to identify study outcomes before Mar. 31, 2002, and ICD-10 codes to identify those diagnosed from Apr. 1, 2002, onward to account for changes in databases over time (Appendix 1, available at www. cmaj.ca/lookup/suppl/doi:10.1503/cmaj.160744/-/DC1]). Prior validation studies suggested that these codes have mid-range sensitivity ( $58 \%$ to $89 \%$ for coronary ischemia and heart failure), excellent specificity (93\% to $97 \%$ for coronary ischemia and heart failure) and a reasonable positive predictive value (65\% to $95 \%$ for thromboembolism, and $90 \%$ to $92 \%$ for stroke or TIA). ${ }^{32-34}$
Secondary outcomes were the individual components of the primary outcome.

Cardiovascular mortality was not included in the primary outcome measure because of the rarity of the event (total mortality was examined in sensitivity analyses).

\section{Statistical analysis}

We compared baseline demographic and clinical characteristics between groups using the $\chi^{2}$ test for categorical variables and the $t$ test for continuous variables. We estimated annualized event rates for the primary and secondary outcomes by dividing the total number of events by the total number of person-years of follow-up. We followed all patients until study termination (Mar. 31, 2015) and included both first and repeat events. We used Poisson regression models with generalized estimating equations to estimate the relative rate ratio and $95 \%$ confidence interval $(\mathrm{Cl})$ of cardiovascular events associated with fertility therapy failure, with time zero set at 1 year following the final fertility treatment.

In multivariable analyses, we adjusted for potential confounders, including age (in years), calendar year, geographic residence (rural v. urban), neighbourhood income (in quintiles), prior health care visits, cardiovascular risk factors (hypertension, diabetes, hypercholesterolemia, smoking and obesity), ischemic heart disease, heart failure, atrial fibrillation, asthma, depression, neoplasm, prior live births, miscarriages and stillbirths, and number of fertility cycles. We performed tests for departure from linearity for continuous variables before estimating a linear association. For patients without recorded diagnoses, we included a code indicating no disease so that all patients could be included in all analyses. We further explored potential effect modification by introducing interaction terms assessing fertility therapy failure with age, type of infertility (primary or secondary) and history of miscarriage. We tested whether a dose-response relationship was present by analyzing results according to whether patients received a single cycle or multiple cycles of fertility therapy.

We conducted survival analyses restricted to the time to first hospital admission for a primary outcome or death using a Cox proportional hazards model, with age as the underlying time variable to derive hazards ratios (HRs) and to check the robustness of the primary analysis. Potential departures from the proportionality assumption were evaluated with the introduction of a time-varying effect term for fertility therapy failure into the multivariable adjusted Cox model.

All $p$ values were 2 -sided, and a threshold less than 0.05 was considered significant. All statistical analyses were performed with the use of SAS version 9.3 (SAS Institute).

\section{Ethics approval}

The Research Ethics Board of Sunnybrook Health Sciences Centre approved the study protocol.

\section{Results}

A total of 28442 women received fertility therapy during the study, of whom 9349 (32.9\%) gave birth and 19093 (67.1\%) did not give birth within 1 year after the final treatment (Table 1). The mean age was 
35.2 (standard deviation 4.8) years, and 23575 (82.9\%) had no prior obstetric deliveries. The median number of fertility cycles was 3 (interquartile range 1-5); 7649 (26.9\%) of the patients received a single cycle of treatment, and 20793 (73.1\%) received multiple cycles.

Fertility therapy failure was most common among women who were older, were living in lower income neighbourhoods, used less health care and had fewer miscarriages or stillbirths. Diabetes and hypertension (including gestational presentations) were the 2 most common traditional cardiovascular risk factors, and each was less common among women who did not give birth following fertility therapy than among those who did $(p<0.001)$. In contrast, hypercholesterolemia $(p<0.001)$, smoking $(p=0.02)$, asthma $(p=0.02)$, neoplasm $(p<0.001)$ and depression $(p=0.03)$ were more common among women who did not give birth following fertility therapy.

During a median follow-up of 8.4 years (interquartile range 5.3-12.4), a total of 2686 primary cardiovascular events were observed among women who underwent fertility therapy, of which 1925 occurred among women who did not subsequently give birth and 761 occurred among those who gave birth. The annual rate of cardiovascular events was $19 \%$ higher among women who did not give birth than among those who did following fertility therapy (1.08 v. 0.91 events per 100 patient-years; relative rate ratio $1.19,95 \% \mathrm{Cl} 1.11-1.27)$. The observed increase persisted after multivariable adjustment (adjusted relative rate ratio $1.21,95 \% \mathrm{Cl} 1.13-1.30)$.

Among the specific components of the primary outcome, a total of 695 outpatient visits were for cerebrovascular events (624 ischemic strokes or TIAs, 71 hemorrhagic strokes), 940 for venothromboembolism, 567 for coronary ischemia and 484 for heart failure. The overall increase in the cardiovascular event rate was explained mostly by increases in the rate of heart failure (adjusted relative rate ratio $2.25,95 \% \mathrm{Cl} 2.06-2.46$ ) and cerebrovascular events (adjusted relative rate ratio 1.25 , 95\% Cl 1.151.37), with an adjusted relative rate ratio of 1.08 for venothromboembolic events $(95 \% \mathrm{Cl} 1.00-1.17)$. In contrast, no increase was observed between fertility therapy failure and coronary ischemia (Table 2). When cerebrovascular risk was further subcategorized, fertility therapy failure was associated with an increased risk of ischemic stroke (adjusted relative rate ratio $1.33,95 \% \mathrm{Cl}$ 1.22-1.46) but not hemorrhagic stroke (adjusted relative rate ratio $0.88,95 \% \mathrm{Cl} 0.80-0.96)$.

In the survival analysis restricted to the time to first hospital admission for the composite outcome of a cardiovascular endpoint or death, the risk was increased among women who had fertility therapy failure compared with women who gave birth following fertility treatment ( 0.11 v. 0.08 events per 100 patientyears; adjusted HR 1.42, 95\% Cl 1.06-1.92) (Figure 1). A check of the consistency of the HR over time with the introduction of a time-dependent interaction term was significant $(p=0.002)$, which suggested departure from the proportional hazards assumption. In particular, the first year of follow-up showed the largest relative risk associated with fertility therapy failure for the composite of hospital admission for a cardiovascular event or death (adjusted HR 4.24, 95\% Cl 1.90-9.44). The trajectory thereafter of cardiovascular risk following fertility therapy failure ap-
Table 1: Baseline characteristics of 28442 women who received fertility therapy*

\begin{tabular}{|c|c|c|c|}
\hline \multirow[b]{2}{*}{ Characteristic } & \multicolumn{2}{|c|}{$\begin{array}{l}\text { Fertility therapy; } \\
\text { no. }(\%) \text { of patients }\end{array}$} & \multirow[b]{2}{*}{$p$ value } \\
\hline & $\begin{array}{c}\begin{array}{c}\text { Failure } \\
n=19093\end{array}\end{array}$ & $\begin{array}{l}\text { Success } \\
n=9349\end{array}$ & \\
\hline Age, yr, median (IQR) & $36(32-39)$ & $34(31-37)$ & $<0.001$ \\
\hline No. of fertility cycles (IQR) & $3(1-5)$ & $3(2-6)$ & $<0.001$ \\
\hline $\begin{array}{l}\text { In vitro fertilization } \\
\text { procedure }\end{array}$ & $2211(11.6)$ & $968(10.4)$ & $<0.001$ \\
\hline Rural residence & $787(4.1)$ & $400(4.3)$ & $<0.001$ \\
\hline \multicolumn{2}{|l|}{ Income quintile } & & $<0.001$ \\
\hline 1 (lowest) & $3202(16.8)$ & $1048(11.2)$ & \\
\hline 2 & $3477(18.2)$ & $1470(15.7)$ & \\
\hline 3 & $3718(19.5)$ & $1877(20.1)$ & \\
\hline 4 & $4221(22.1)$ & $2354(25.2)$ & \\
\hline 5 (highest) & $4416(23.1)$ & $2591(27.7)$ & \\
\hline Unknown & $59(0.3)$ & $9(0.1)$ & \\
\hline $\begin{array}{l}\text { Prior obstetric } \\
\text { delivery }\end{array}$ & $3167(16.6)$ & $1700(18.2)$ & $<0.001$ \\
\hline $\begin{array}{l}\text { Any visit to emergency } \\
\text { department in prior year }\end{array}$ & $903(4.7)$ & $688(7.4)$ & $<0.001$ \\
\hline $\begin{array}{l}\text { Any hospital admission } \\
\text { in prior year }\end{array}$ & $4193(22.0)$ & $2277(24.4)$ & $<0.001$ \\
\hline History of miscarriage & $3095(16.2)$ & $1700(18.2)$ & $<0.001$ \\
\hline History of stillbirth & $50(0.3)$ & $63(0.7)$ & $<0.001$ \\
\hline $\begin{array}{l}\text { Hypertension, including } \\
\text { gestational hypertension }\end{array}$ & 729 (3.8) & $656(7.0)$ & $<0.001$ \\
\hline $\begin{array}{l}\text { Diabetes, including } \\
\text { gestational diabetes }\end{array}$ & 599 (3.1) & $964(10.3)$ & $<0.001$ \\
\hline Hypercholesterolemia & $522(2.7)$ & $98(1.0)$ & $<0.001$ \\
\hline Smoking & $34(0.2)$ & $6(0.1)$ & 0.02 \\
\hline Obesity & $435(2.3)$ & $125(1.3)$ & $<0.001$ \\
\hline Asthma & $792(4.1)$ & $334(3.6)$ & 0.02 \\
\hline Neoplasm & $454(2.4)$ & $90(1.0)$ & $<0.001$ \\
\hline Depression & $585(3.1)$ & $244(2.6)$ & 0.03 \\
\hline $\begin{array}{l}\text { Systemic autoimmune } \\
\text { rheumatic disease }\end{array}$ & $843(4.4)$ & 367 (3.9) & 0.3 \\
\hline Atrial fibrillation & $267(1.4)$ & $165(1.8)$ & 0.02 \\
\hline Ischemic heart disease & $174(0.9)$ & $62(0.7)$ & 0.03 \\
\hline Cardiomyopathy & $21(0.1)$ & $32(0.3)$ & $<0.001$ \\
\hline Cerebrovascular disease & $50(0.3)$ & $27(0.3)$ & 0.7 \\
\hline $\begin{array}{l}\text { Thromboembolic } \\
\text { disease }\end{array}$ & $10(0.1)$ & $9(0.1)$ & 0.2 \\
\hline $\begin{array}{l}\text { Pulmonary circulation } \\
\text { disease }\end{array}$ & $25(0.1)$ & $13(0.1)$ & 0.9 \\
\hline $\begin{array}{l}\text { Note: IQR = interquartile range. } \\
\text { "Baseline characteristics were as } \\
\text { fertility treatment except for histo } \\
\text { which were ascertained over the } \\
\text { tUnless stated otherwise. }\end{array}$ & $\begin{array}{l}\text { ned during th } \\
\text { live births, } m \\
\text { ion of availab }\end{array}$ & $\begin{array}{l}\text { ears before the } \\
\text { iages and still } \\
\text { a. }\end{array}$ & $\begin{array}{l}\text { e of final } \\
\text { s, data for }\end{array}$ \\
\hline
\end{tabular}


Table 2: Long-term outpatient cardiovascular outcomes following fertility therapy failure

\section{Fertility therapy}

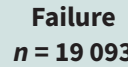

Outcome

Any cardiovascular event

Coronary ischemia

Heart failure

Venothromboembolism

Cerebrovascular events

Ischemic stroke/TIA

Hemorrhagic stroke
No.

Rate†

1.08

0.22

0.20

0.37

0.29

0.26

0.025
Success

$n=9349$
Relative rate ratio* $(95 \% \mathrm{CI})$

\begin{tabular}{cccc} 
No. & Rate & Unadjusted & Adjusted \\
\hline 761 & 0.91 & $1.19(1.11-1.27)$ & $1.21(1.13-1.30)$ \\
175 & 0.21 & $1.05(0.98-1.13)$ & $0.86(0.80-0.93)$ \\
132 & 0.16 & $1.25(1.15-1.37)$ & $2.25(2.06-2.46)$ \\
272 & 0.32 & $1.15(1.07-1.25)$ & $1.08(1.00-1.17)$ \\
182 & 0.22 & $1.32(1.22-1.44)$ & $1.25(1.15-1.37)$ \\
156 & 0.19 & $1.41(1.29-1.54)$ & $1.33(1.22-1.46)$ \\
\hline 26 & 0.031 & $0.81(0.75-0.89)$ & $0.88(0.80-0.96)$
\end{tabular}

Note: $\mathrm{Cl}=$ confidence interval, $\mathrm{TI} \mathrm{A}=$ transient ischemic attack

*Rate ratios represent frequency among women following fertility therapy failure compared with those following successful fertility therapy.

†Absolute rates denote events per 100 patient-years of follow-up.

$\ddagger$ Adjusted for age, calendar year, geographic residence, neighbourhood income quintile, prior health care visits, cardiovascular risk factors (e.g., hypertension, diabetes,

hypercholesterolemia, smoking and obesity), history of ischemic heart disease, heart failure, atrial fibrillation, asthma, depression, neoplasm, prior live births, miscarriages and stillbirths, and number of fertility cycles.

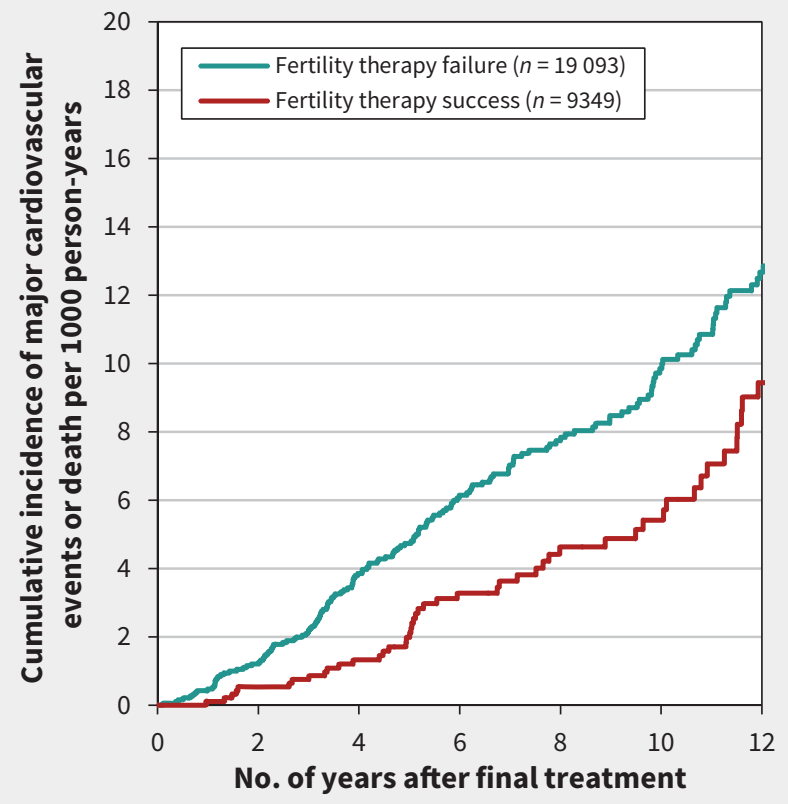

Figure 1: Cumulative incidence of major cardiovascular events or death per 1000 patient-years following fertility therapy failure or success.

proached that of cardiovascular risk following successful fertility therapy by about 5 years after final treatment. Restriction of the survival analysis to focus only on the time to first hospital admission for a cardiovascular event resulted in similar results, with the highest relative risk in the first year of follow-up (adjusted HR $3.21,95 \% \mathrm{Cl} 1.24-8.34$ ).

We observed no statistically significant heterogeneity in cardiovascular risk associated with fertility therapy failure across subgroups (all interaction $p$ values $>0.1$ ), except possibly according to history of miscarriage (interaction $p=0.06$ ). In this subgroup, the increased risk appeared accentuated among women with a history of miscarriage (Figure 2). Of note, no subgroup showed a lower subsequent risk of adverse cardiovascular events associated with fertility therapy failure, including women who underwent only a single cycle of treatment (Figure 3).

\section{Interpretation}

In our cohort of more than 28000 women, fertility therapy failure was common and was associated with an increased risk of adverse cardiovascular events. The largest relative increases were for heart failure and cerebrovascular events. The overall higher relative risk of cardiovascular events associated with fertility therapy failure was observed in diverse demographic subgroups, irrespective of the number of fertility treatment cycles and regardless of whether the diagnosis was primary or secondary infertility. The increased risk was particularly high among women with a prior miscarriage. The absolute risk was modest and the relative risk was mostly confined to the first 5 years following fertility therapy.

Several mechanisms may underlie our findings, as suggested by past studies linking fertility therapy, ovarian hyperstimulation and vascular complications. ${ }^{10,11}$ Prior population-based reports of women receiving fertility therapy (including in vitro fertilization) indicated an increased risk of pulmonary embolism throughout pregnancy, post partum ${ }^{10,11}$ and over subsequent years. ${ }^{12} \mathrm{An}$ increased risk of thrombosis persists after the birth of a child conceived with the help of fertility therapy and may extend to women following fertility therapy failure. The risk may become increasingly relevant as more women with comorbidities contemplate reproduction with fertility therapy. ${ }^{35,36}$ The risk may also become more relevant as specific employers propose oocyte cryopreservation for future fertility as a workplace benefit. ${ }^{37,38}$ 
The cause of cerebrovascular events and heart failure following fertility therapy failure is likely complex..$^{8,9,39}$ One potential mechanism is direct activation of the renin-angiotensin system with ovarian hyperstimulation, ${ }^{13-15}$ which influences systemic vascular permeability, sodium balance and blood pressure. ${ }^{16}$ Fluid shifts may result in depletion of intravascular volume and interstitial edema that mediates ischemic stroke, heart failure and venothromboembolic risks during pregnancy and potentially thereafter.

Whether these cardiovascular events could be prevented by long-term renin-angiotensin inhibitor therapy is a topic for future research, although some short-term success has been described for the early adverse effects of ovarian hyperstimulation. ${ }^{40,41}$ Additional potential options to protect against thromboembolism might include the control of risk factors or prophylactic antiplatelet therapy. ${ }^{42}$ In contrast, an observed decreased risk of coronary events following fertility therapy failure appears inconsistent with the hypothesis that endothelial dysfunction may already be present in women at risk of miscarriage and may become accentuated by fertility therapy failure. ${ }^{19}$

Alternatively, fertility treatment may be innocuous and merely unmask a latent predisposition to premature cardiovascular disease among individuals at risk of infertility. ${ }^{22-25,43}$ Our prior research showed that women who delivered following fertility therapy had more short-term adverse cardiometabolic events but lower long-term cardiovascular risk compared with women who

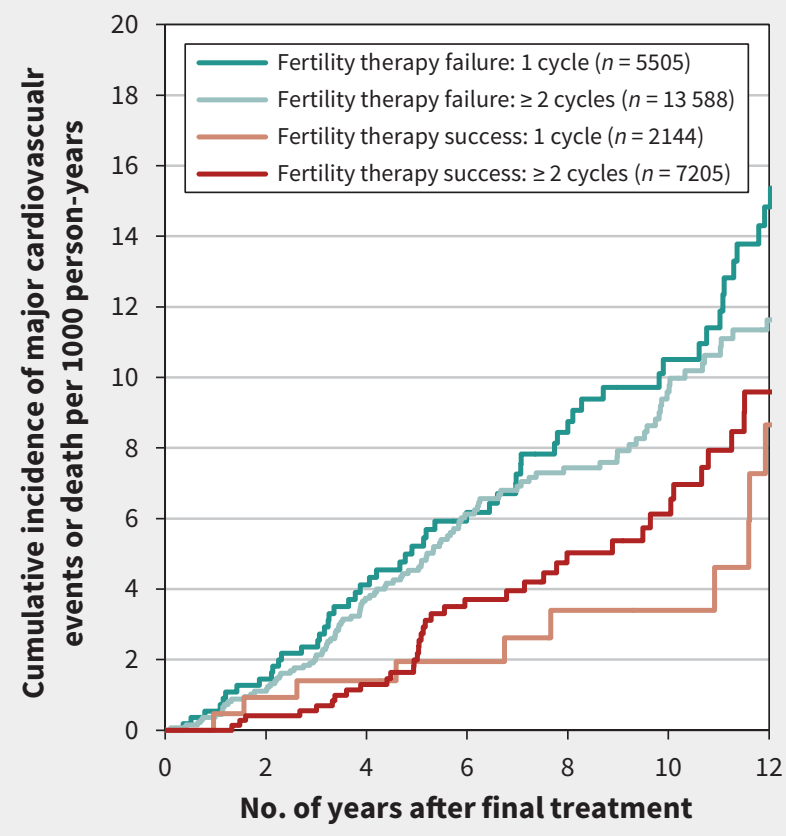

Figure 3: Cumulative incidence of major cardiovascular events or death per 1000 patient-years following fertility therapy failure or success, stratified by number of treatment cycles.

\begin{tabular}{|c|c|c|c|c|c|c|}
\hline \multirow[b]{2}{*}{ Variable } & \multicolumn{2}{|c|}{ Fertility therapy } & \multirow[b]{2}{*}{$\begin{array}{l}\text { Adjusted rate ratio } \\
(95 \% \mathrm{Cl})\end{array}$} & \multirow[b]{2}{*}{$\begin{array}{c}\text { Interaction } \\
p \text { value }\end{array}$} & \multirow[b]{2}{*}{$\begin{array}{l}\text { Decreased } \\
\longleftarrow \text { risk }\end{array}$} & \multirow[b]{2}{*}{$\begin{array}{l}\text { Increased } \\
\text { risk } \longrightarrow\end{array}$} \\
\hline & $\begin{array}{c}\text { Failure } \\
\text { Events/Total }\end{array}$ & $\frac{\text { Success }}{\text { Events/Total }}$ & & & & \\
\hline Overall & $1925 / 19093$ & $761 / 9349$ & $1.21(1.13-1.30)$ & \multirow{3}{*}{0.2} & & \\
\hline \multicolumn{7}{|l|}{ Age, yr } \\
\hline$<35$ & $667 / 7677$ & $400 / 5048$ & $1.20(1.05-1.37)$ & & & - \\
\hline$\geq 35$ & $1258 / 11416$ & $361 / 4301$ & $1.33(1.17-1.50)$ & & & \\
\hline \multicolumn{7}{|c|}{ No. of fertility cycles } \\
\hline 1 & $660 / 5505$ & $200 / 2144$ & $1.19(1.01-1.42)$ & \multirow{2}{*}{0.6} & & \\
\hline$\geq 2$ & $1265 / 13588$ & $561 / 7205$ & $1.25(1.13-1.39)$ & & & - \\
\hline \multicolumn{7}{|c|}{ Type of infertility } \\
\hline Primary & $1628 / 15926$ & $620 / 7649$ & $1.26(1.14-1.39)$ & \multirow{2}{*}{0.6} & & \\
\hline Secondary & $297 / 3167$ & $141 / 1700$ & $1.13(0.92-1.40)$ & & & \\
\hline \multicolumn{7}{|c|}{ Prior miscarriage } \\
\hline Absent & $1536 / 15998$ & $607 / 7649$ & $1.17(1.06-1.30)$ & \multirow{2}{*}{0.06} & & \\
\hline \multirow[t]{3}{*}{ Present } & $389 / 3095$ & $154 / 1700$ & $1.48(1.21-1.81)$ & & & 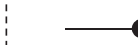 \\
\hline & & & & & $0.50 \quad 1$. & \\
\hline & & & & & \multicolumn{2}{|c|}{ Relative rate ratio $(95 \% \mathrm{CI})$} \\
\hline
\end{tabular}

Figure 2: Risk of cardiovascular events or death following fertility therapy failure versus fertility therapy success, stratified by baseline risk factors. Adjusted rate ratios greater than 1.0 indicate an increased risk following fertility therapy failure. Error bars $=95 \%$ confidence intervals, $\mathrm{Cl}=$ confidence interval. 
gave birth without assisted reproductive treatment. ${ }^{2}$ In the current study, we reduced confounding by the propensity of healthier women to receive fertility therapy, a bias that might mask potential detrimental biologic consequences. Together, these findings are consistent with the hypothesis that fertility therapy failure may represent an early indication for future cardiovascular disease because it represents a unique cardiometabolic stress test. As a result, the time following fertility therapy may be an opportunity to identify young women at increased risk of future cardiovascular events and initiate early strategies to modify risk factors (an opportunity that is currently unrecognized). This interpretation, however, warrants confirmation in further studies.

\section{Limitations}

Our approach provided a comprehensive evaluation of women following fertility therapy, yet the results should be interpreted with caution. In particular, we could not ascertain less invasive forms of fertility therapy, and information was not available about other clinical factors not detailed in administrative data, such as blood pressure, cholesterol levels and ventricular function. We could not distinguish among early types of fertility therapy failure and a small number of women who may have undergone ovarian induction for fertility preservation or egg donation. Although we could not definitively address whether successive cycles of fertility therapy were associated with increased cardiovascular risk, future studies using propensity-based methodology seem warranted to minimize selection bias and reduce confounding by indication. Finally, we combined diverse cardiovascular events for our composite outcome, which should be interpreted with caution because underlying mechanisms and risk factors may be different.

\section{Conclusion}

Fertility therapy failure was associated with an increased risk of long-term adverse cardiovascular events. A potential increase in cardiovascular events may become increasingly relevant with broader utilization of fertility therapy and longer follow-up. More informed decision-making around reproductive technology requires an awareness of potential risks and the need for continued long-term clinical care. Fertility therapy failure may be another sex-specific cardiovascular risk factor that warrants further research to identify women who may benefit from a cardiovascular risk evaluation.

\section{References}

1. Stephen EH, Chandra A, King RB. Supply of and demand for assisted reproductive technologies in the United States: clinic- and population-based data, 1995-2010. Fertil Steril 2016;105:451-8.

2. Udell JA, Lu H, Redelmeier DA. Long-term cardiovascular risk in women prescribed fertility therapy. J Am Coll Cardiol 2013;62:1704-12.

3. Dayan N, Laskin CA, Spitzer K, et al. Pregnancy complications in women with heart disease conceiving with fertility therapy. J Am Coll Cardiol 2014;64:1862-4.

4. Kawwass JF, Kissin DM, Kulkarni AD, et al. Safety of assisted reproductive technology in the United States, 2000-2011. JAMA 2015;313:88-90.

5. Qin J, Liu X, Sheng X, et al. Assisted reproductive technology and the risk of pregnancy-related complications and adverse pregnancy outcomes in singleton pregnancies: a meta-analysis of cohort studies. Fertil Steril 2016;105:73-85.e1-6.

6. Qin J, Wang H, Sheng X, et al. Pregnancy-related complications and adverse pregnancy outcomes in multiple pregnancies resulting from assisted reproductive technology: a meta-analysis of cohort studies. Fertil Steril 2015; 103:1492-508.e1-7.
7. Roos-Hesselink JW, Johnson MR. Does fertility therapy hamper cardiovascular outcome? J Am Coll Cardiol 2013;62:1713-4.

8. Binder H, Dittrich R, Einhaus F, et al. Update on ovarian hyperstimulation syndrome: Part 1 - Incidence and pathogenesis. Int J Fertil Womens Med 2007; 52:11-26.

9. Vloeberghs V, Peeraer K, Pexsters A, et al. Ovarian hyperstimulation syndrome and complications of ART. Best Pract Res Clin Obstet Gynaecol 2009;23:691-709.

10. Henriksson $P$, Westerlund $E$, Wallén $\mathrm{H}$, et al. Incidence of pulmonary and venous thromboembolism in pregnancies after in vitro fertilisation: cross sectional study. BMJ 2013;346:e8632.

11. Hansen AT, Kesmodel US, Juul S, et al. Increased venous thrombosis incidence in pregnancies after in vitro fertilization. Hum Reprod 2014;29:611-7.

12. Hansen AT, Kesmodel US, Juul S, et al. No evidence that assisted reproduction increases the risk of thrombosis: a Danish national cohort study. Hum Reprod 2012;27:1499-503.

13. Gonçalves PB, Ferreira R, Gasperin B, et al. Role of angiotensin in ovarian follicular development and ovulation in mammals: a review of recent advances. Reproduction 2012;143:11-20.

14. Morris RS, Paulson RJ. Increased angiotensin-converting enzyme activity in a patient with severe ovarian hyperstimulation syndrome. Fertil Steril 1999; 71:562-3.

15. Morris RS, Wong IL, Kirkman E, et al. Inhibition of ovarian-derived prorenin to angiotensin cascade in the treatment of ovarian hyperstimulation syndrome. Hum Reprod 1995;10:1355-8.

16. Hassan E, Creatsas G, Mastorakos G, et al. Clinical implications of the ovarian/ endometrial renin-angiotensin-aldosterone system. Ann N Y Acad Sci 2000;900: 107-18.

17. Smith GC, Pell JP, Walsh D. Pregnancy complications and maternal risk of ischaemic heart disease: a retrospective cohort study of 129,290 births. Lancet 2001;357:2002-6.

18. Smith GC, Pell JP, Walsh D. Spontaneous loss of early pregnancy and risk of ischaemic heart disease in later life: retrospective cohort study. BMJ 2003; 326:423-4.

19. Germain AM, Romanik MC, Guerra I, et al. Endothelial dysfunction: A link among preeclampsia, recurrent pregnancy loss, and future cardiovascular events? Hypertension 2007;49:90-5

20. Cuevas AM, Germain AM. A failed pregnancy stress test: a new and under-recognized cardiovascular risk factor. Curr Atheroscler Rep 2011;13:285-6.

21. Ranthe MF, Andersen EAW, Wohlfarht J, et al. Pregnancy loss and later risk of atherosclerotic disease. Circulation 2013;127:1775-82.

22. Parikh NI, Cnattingius S, Mittleman MA, et al. Subfertility and risk of later life maternal cardiovascular disease. Hum Reprod 2012;27:568-75.

23. Eisenberg ML, Li S, Cullen MR, et al. Increased risk of incident chronic medical conditions in infertile men: analysis of United States claims data. Fertil Steril 2016;105:629-36

24. Park K, Wei J, Minissian M, et al. Adverse pregnancy conditions, infertility, and future cardiovascular risk: implications for mother and child. Cardiovasc Drugs Ther 2015;29:391-401.

25. Kurabayashi T, Mizunuma H, Kubota $\mathrm{T}$, et al. Ovarian infertility is associated with cardiovascular disease risk factors in later life: a Japanese cross-sectional study. Maturitas 2016;83:33-9.

26. Wilmot KA, O'Flaherty M, Capewell S, et al. Coronary heart disease mortality declines in the United States from 1979 through 2011: evidence for stagnation in young adults, especially women. Circulation 2015;132:997-1002.

27. Schedule of benefits for physician services under the Health Insurance Act. Toronto: Ontario Ministry of Health and Long-Term Care; 2015. Available: www.health.gov. on.ca/english/providers/program/ohip/sob/physserv/physserv_mn.html (accessed 2015 Dec. 21).

28. Williams JI, Young W. A summary of studies on the quality of health care administrative databases in Canada. In: Goel V, Williams JI, Anderson GM, et al., editors. Patterns of health care in Ontario: the ICES Practice Atlas. 2nd ed. Ottawa: Canadian Medical Association; 1996:339-45.

29. Joseph KS, Fahey J. Validation of perinatal data in the Discharge Abstract Database of the Canadian Institute for Health Information. Chronic Dis Can 2009;29:96-100.

30. Hux JE, Ivis F, Flintoft V, et al. Diabetes in Ontario: determination of prevalence and incidence using a validated administrative data algorithm. Diabetes Care 2002;25:512-6.

31. Tu K, Campbell NR, Chen ZL, et al. Accuracy of administrative databases in identifying patients with hypertension. Open Med 2007;1:e18-26.

32. Austin PC, Daly PA, Tu JV. A multicenter study of the coding accuracy of hospital discharge administrative data for patients admitted to cardiac care units in Ontario. Am Heart J 2002;144:290-6.

33. Kokotailo RA, Hill MD. Coding of stroke and stroke risk factors using international classification of diseases, revisions 9 and 10. Stroke 2005;36:1776-81. 
34. Tamariz L, Harkins T, Nair V. A systematic review of validated methods for identifying venous thromboembolism using administrative and claims data. Pharmacoepidemiol Drug Saf 2012;21(Suppl 1):154-62.

35. ESHRE Capri Workshop Group. Venous thromboembolism in women: a specific reproductive health risk. Hum Reprod Update 2013;19:471-82.

36. Somigliana E, Peccatori FA, Filippi F, et al. Risk of thrombosis in women with malignancies undergoing ovarian stimulation for fertility preservation. Hum Reprod Update 2014;20:944-51.

37. Bennet J. Company-paid egg freezing will be the great equalizer. Time 2014 Oct. 15. Available: http://time.com/3509930/company-paid-egg-freezing-will-be-the-great -equalizer/ (accessed 2016 Jan. 21).

38. Petropanagos A, Cattapan A, Baylis F, et al. Social egg freezing: risk, benefits and other considerations. CMAJ 2015;187:666-9.
39. Jing Z, Yanping L. Middle cerebral artery thrombosis after IVF and ovarian hyperstimulation: a case report. Fertil Steril 2011;95:2435.e13-5.

40. Ata $\mathrm{B}$, Yakin $\mathrm{K}$, Alatas $\mathrm{C}$, et al. Dual renin-angiotensin blockage and total embryo cryopreservation is not a risk-free strategy in patients at high risk for ovarian hyperstimulation syndrome. Fertil Steril 2008;90:531-6.

41. Ando H, Furugori K, Shibata D, et al. Dual renin-angiotensin blockade therapy in patients at high risk of early ovarian hyperstimulation syndrome receiving IVF and elective embryo cryopreservation: a case series. Hum Reprod 2003; 18:1219-22.

42. Bates SM. Anticoagulation and in vitro fertilization and ovarian stimulation. Hematology Am Soc Hematol Educ Program 2014;2014:379-86.

43. Jensen TK, Jacobsen R, Christensen K, et al. Good semen quality and life expectancy: a cohort study of 43,277 men. Am J Epidemiol 2009;170:559-65.
Competing interests: Jacob Udell has received honoraria for consultant or advisory relationships with Janssen, Merck, Novartis, Sanofi Pasteur and Amgen; research support from Novartis for participation as a site investigator in the PARAGON-HF trial; honoraria from Novartis for steering committee membership in the PARTHENON trial; and honoraria for sponsored lectures from Janssen. No other competing interests were declared.

This article has been peer reviewed.

Affiliations: Women's College Hospital and Toronto General Hospital (Udell), University of Toronto; Institute for Clinical Evaluative Sciences (Udell, Lu); Department of Medicine (Redelmeier), Sunnybrook Health Sciences Centre, University of Toronto; Evaluative Clinical Sciences (Redelmeier), Sunnybrook Research Institute, Toronto, Ont.

Contributors: All of the authors conceived and designed the study and wrote the statistical analysis plan. Hong Lu was responsible for data acquisition. All of the authors analyzed and interpreted the data. Jacob Udell and Donald Redelmeier obtained funding. Donald Redelmeier pro- vided administrative, technical and material support. Jacob Udell wrote the first draft of the paper. All of the authors critically revised the manuscript for important intellectual content, approved the final version to be published and agreed to act as guarantors of the work.

Funding: This work was supported by the Heart and Stroke Foundation of Canada (grant no. G-15-0009034) and the Canada Research Chair in Medical Decision Science. Jacob Udell is supported in part by a Heart and Stroke Foundation of Canada National New Investigator/Ontario Clinician Scientist Award, the Heart and Stroke Foundation Emerging Research Leaders Initiative (grant no. ERLI024), the Ontario Ministry of Research, Innovation and Science (grant no. ER15-11-037), Women's College Research Institute and Department of Medicine, Women's College Hospital; Peter Munk Cardiac Centre, University Health Network; Department of Medicine and Heart and Stroke Richard Lewar Centre of Excellence in Cardiovascular Research, University of Toronto. The funding agencies had no role in the design or conduct of the study, the collection, management, analysis or interpretation of the data, the preparation, review or approval of the manuscript, or the decision to submit for publication.

Acknowledgements: The authors thank Drs. Deva Thiruchelvam, Jon Barrett, Alex Kopp and Carl Laskin for their helpful review of earlier versions of this manuscript. No compensation was provided for their assistance.

Disclosure: This study was supported by the Institute for Clinical Evaluative Sciences (ICES), which is funded by an annual grant from the Ontario Ministry of Health and Long-Term Care (MOHLTC). The opinions, results and conclusions reported in this paper are those of the authors and are independent from the funding sources. No endorsement by ICES or the Ontario MOHLTC is intended or should be inferred. Parts of this material are based on data and information compiled and provided by the Canadian Institute for Health Information (ClHI). However, the analyses, conclusions, opinions and statements expressed herein are those of the authors and not necessarily those of $\mathrm{ClHI}$.

Accepted: Nov. 29, 2016

Correspondence to: Jacob Udell, jay.udell@utoronto.ca 